\title{
Optimization of microwave-assisted extraction and the effect of microencapsulation on mangosteen (Garcinia mangostana L.) rind extract
}

\author{
Choi-Wen HIEW ${ }^{1}$, Li-Juan LEE ${ }^{1}$, Silvara JUNUS² (D), Yen-Nee TAN ${ }^{1,3}$ (D), Tsun-Thai CHAI ${ }^{1,3}$ (D), Kah-Yaw EE ${ }^{1,3 *}$ (D)
}

\begin{abstract}
The effects of optimization of microwave-assisted extraction (MAE) and microencapsulation on the total xanthone content (TXC), total phenolic content (TPC), and antioxidant activity of mangosteen rind extract were studied. Response surface methodology (RSM) was employed with Box-Behnken design to generate fifteen optimization responses by incorporating three independent variables, namely soaking time, solvent-to-feed (S/F) ratio and extraction time. The highest extraction yield (19.43\%) was obtained in the third response. TXC and TPC results fitted well, with high R-squared values (0.83-0.91), into the generated models, but not the antioxidant activity data. The interactive effects of $\mathrm{S} / \mathrm{F}$ ratio and extraction time significantly increased the yields of TXC (46.62 mg a-mangostin/g crude extract) and TPC (46.30 mg gallic acid equivalent/g crude extract), but longer soaking time showed adverse effect. All the results obtained from the optimized models were validated using experimental data which showed desirability index of 0.88 . The optimized parameters of MAE were established as 20:1 S/F ratio and 9 min extraction time, without soaking process. Despite the intact morphology of microcapsules observed, spray drying microencapsulation only preserved TXC partially (63.54\%) but denatured more than $85 \%$ of TPC. Future investigation on the microencapsulation of mangosteen rind extract is required.
\end{abstract}

Keywords: response surface methodology; microwave-assisted extraction; spray drying microencapsulation; total xanthone content; total phenolic content.

Practical Application: Optimization of phytochemical extraction from mangosteen rind and spray drying microencapsulation process.

\section{Introduction}

Mangosteen (Garcinia mangostana Linn.) is a tropical fruit that can be commonly found in the South-East Asia. The fruit has edible white aril with refreshing sweet-sour taste and pleasant aroma, thus gaining it the prestige as the "Queen of fruits" (Makhonpas et al., 2015). Apart from this, the dark purple mangosteen rind, which is usually treated as agricultural waste, has become the most popular source of xanthone, a plant secondary metabolite with numerous health promoting effects, such as antioxidant, antimicrobial, anti-inflammatory, and anti-proliferative properties (Jung et al., 2006; Pothitirat \& Gritsanapan, 2008; Shibata et al., 2013; Chen et al., 2008; Sutono, 2013; Tjahjani et al., 2014; Bumrungpert et al., 2010; Johnson et al., 2012). Xanthones are the polyphenol compounds that usually occur in the higher plant families (Negi et al., 2013). To date, approximately 650 xanthones have been discovered from the natural resources (Mazimba et al., 2013). The $\alpha$-mangostin $\left(\mathrm{C}_{24} \mathrm{H}_{26} \mathrm{O}_{6}\right)$ is the major type of xanthones that is present in the mangosteen rind, followed by low amounts of other xanthone derivatives, such as garcinone, gartanin, mangostanol and mangostanin (Sukatta et al., 2013; Widowati et al., 2014; Wittenauer et al., 2012).
Although mangosteen rind contains a substantial amount of phytocompounds that benefit human health, they are very susceptible to the environmental factors during extraction and processing stages. Despite the great efforts made in commercializing mangosteen rind xanthone as nutraceutical supplements, herbal cosmetics and pharmaceutical products, the knowledge of effective extraction is currently very limited. The conventional methods, such as maceration, Soxhlet extraction and heat reflux, are found to be time-consuming, high in operating costs and low in product recovery (Fang et al., 2011). Nevertheless, a study of Satong-aun et al. (2011) suggested that microwave-assisted extraction (MAE) could be employed to replace the conventional extraction methods and enhance the yield of $\alpha$-mangostin while at the same time shortening the extraction time and lessening the amount of solvent required. Microwave heating generates high pressure in the plant cells and causes damage to the cell wall, thus releasing all the phytocompounds (Veggi et al., 2013). Additionally, soaking the plant matrix in solvents could be applied as a pre-treatment process to increase the yield of the plant matrices. The ether linkages in cellulose will be hydrolyzed and the soluble fractions are formed in a short period (Tatke \& Jaiswal, 2011). Furthermore, the solvent-to-feed (S/F) ratio 
should also be considered as one of the critical factors because the volume of solvent used will indicate the energy consumption and affect the overall yield of xanthone. Bringing all these factors together, further studies are warranted on the optimization of MAE parameters. In the present study, response surface methodology (RSM) was applied in order to achieve optimized conditions for MAE. The individual variables or parameters were analyzed using Box-Behnken design with transformed value of $-1,0$, and 1 (Ferreira et al., 2007; Francis et al., 2003). These outcomes could illustrate the correlation between responses and factors.

The functional stability of the xanthone extract could be susceptible to the environmental factors, for example oxygen, light, temperature and moisture (Fang \& Bhandari, 2011). Several chemical and mechanical approaches could be applied to preserve its bioactivity during production and storage. Considering cost effectiveness, a mechanical method such as microencapsulation would be an appropriate option. Microencapsulation refers to a process in which the active components are enclosed within a polymeric coating film to form the small particles known as microcapsules (Böger et al., 2018). Generally, the bioactive material, which is known as the core of the microcapsule, is surrounded by the wall material, which is known as coating or shell. The microcapsules are typically spherical in shape with various sizes between 0.05 to $2000 \mu \mathrm{m}$ (Singh, et al., 2010). Spray drying is one of the conventional techniques employed for mechanical microencapsulation in food industries. This technique is commonly used to process heat-sensitive compounds, mainly because of its rapid evaporation rate of water with low core temperature (Ballesteros et al., 2017; Aliakbarian et al., 2018). Therefore, this study was conducted to establish the optimized parameters for MAE and analyze the effects of MAE and microencapsulation processes on TXC, TPC and antioxidant activity of mangosteen rind extract.

\section{Materials and methods}

\subsection{Materials}

The fresh rind of mangosteen (Garcinia mangostana L.) was sourced from MaoShanWang Durian Sdn. Bhd., a local orchard in Malaysia. The rind was rinsed with distilled water and cut into small pieces manually. Then, they were dried immediately using a drying oven (Binder, Germany) at $60^{\circ} \mathrm{C}$ until a constant weight was obtained. After that, the dried mangosteen rind was ground into powder using IKA A11 basic analytical mill (IKA, Malaysia). The mangosteen rind powder was stored in a freezer $\left(-20^{\circ} \mathrm{C}\right)$ prior to analysis. All reagents and chemicals were of analytical grade and purchased from Sigma Aldrich, USA; Merck, Germany; Fisher Scientific, Malaysia; and Tokyo Chemical Industry Co., Ltd., Japan.

\subsection{Experimental design for optimization}

RSM was applied with Box-Behnken design using JMP ${ }^{\circledR}$ statistical software. According to Table 1, fifteen optimization responses, including three central points, were generated from the three extraction parameters (independent variables) at three levels. The experimental data were subjected to the Equation 1 below:
$\mathrm{Y}=b_{0}+b_{1} X_{1}+b_{2} X_{2}+b_{3} X_{3}+b_{11}+b_{22}+b_{33}+b_{12} X_{1} X_{2}+b_{13} X_{1} X_{3}+b_{23} X_{2} X_{3}$

where $\mathrm{Y}=$ responses (total xanthone content, total phenolic content, antioxidant activity); $\mathrm{X}=$ independent variables (soaking time, S/F ratio, extraction time); $\mathrm{b}_{0}=$ intercept; $\mathrm{b}_{1}, \mathrm{~b}_{2}$ and $\mathrm{b}_{3}=$ linear regression coefficients; $\mathrm{b}_{11}, \mathrm{~b}_{22}$ and $\mathrm{b}_{33}=$ quadratic regression coefficients; $\mathrm{b}_{12}, \mathrm{~b}_{13}$ and $\mathrm{b}_{23}=$ interaction coefficients.

\subsection{Validation of RSM models}

The optimized parameters from the RSM models were validated by performing the MAE accordingly. The experimental results obtained were then compared to those predicted by the models.

\subsection{Microwave-assisted extraction and yield determination}

Mangosteen rind powder was mixed with distilled water to obtain the S/F ratios as shown in Table 1 . The mixture was gently agitated using a shaking incubator at room temperature $\left(25^{\circ} \mathrm{C}\right)$ to achieve the soaking time of $1 \mathrm{~h}$ and $2 \mathrm{~h}$. Then, extraction was carried out using a microwave digestion system (Milestone Srl., Italy) at $270 \mathrm{~W}$ for $3 \mathrm{~min}, 6 \mathrm{~min}$ and $9 \mathrm{~min}$. After extraction, the homogenates were centrifuged at $2935 \times \mathrm{g}$ for $10 \mathrm{~min}$ using a tabletop centrifuge G16-C (Sartorius Lab Instruments GmbH \& Co. KG, Germany). Then, the supernatant was collected, filtered through 45-micron disposable syringe filter, and dried in a drying oven at $40{ }^{\circ} \mathrm{C}$ to achieve a constant weight. The oven-dried sample was then stored at $-20^{\circ} \mathrm{C}$ prior to analysis. The total yield of the sample was obtained by weighing the dried extract and calculated using the Equation 2 below:

Yield $(\%)=\frac{\text { Mass }(g) \text { of dried extract }}{\text { Mass }(g) \text { of ground powder }} \times 100 \%$

\subsection{Microencapsulation process}

The dried mangosteen rind extract was firstly reconstituted with distilled water to achieve the total soluble solid of $0.3^{\circ} \mathrm{Brix}$. Then, the extract was homogenized with $2 \%(\mathrm{w} / \mathrm{v})$ sodium alginate solution, which was used as wall material, at an optimal extract-to-sodium alginate ratio of 1:3 (v/v) (Garofulic et al., 2017). The process of microencapsulation was performed mechanically using a Laboratory Scale Spray Dryer (Lab-Plant SD-06, U.K.) according to a procedure of Waterhouse et al. (2017). The spray dryer system was monitored at inlet temperature of $180^{\circ} \mathrm{C}$, fan speed of $3.5 \mathrm{~m} / \mathrm{s}$ and atomization pressure of $250 \mathrm{kPa}$. It was operated with distilled water for 10 min prior to feeding the sample into the equipment. After the spray drying process, the dried powder was collected and stored in a desiccator at room temperature prior to analysis.

Table 1. Independent variables with levels in Box-Behnken design.

\begin{tabular}{llccc}
\hline & \multirow{2}{*}{ Independent variables } & \multicolumn{3}{c}{ Levels } \\
\cline { 2 - 5 } & & Low & Medium & High \\
\hline $\mathrm{X}_{1}$ & Soaking time $(\mathrm{h})$ & 0 & 1 & 2 \\
$\mathrm{X}_{2}$ & Solvent-to-feed (S/F) ratio & $10: 1$ & $15: 1$ & $20: 1$ \\
$\mathrm{X}_{3}$ & Extraction time (min) & 3 & 6 & 9 \\
Transformed value & -1 & 0 & 1 \\
\hline
\end{tabular}




\subsection{Determination of total xanthone content}

TXC in mangosteen rind extract was determined using a procedure reported by Aisha et al. (2013) with slight modification. Firstly, $20 \mu \mathrm{g} / \mathrm{mL}$ sample was prepared in $80 \%$ (v/v) methanol. The absorbance of the mixture was read in a quartz cuvette at $243.4 \mathrm{~nm}$ using a UV-Vis spectrophotometer (Thermo Scientific, US). A standard curve was prepared using $\alpha$-mangostin solution $(0-20 \mu \mathrm{g} / \mathrm{mL}$ in $80 \%(\mathrm{v} / \mathrm{v})$ methanol). TXC was expressed as milligram of $\alpha$-mangostin equivalent per gram of dry extract.

\subsection{Determination of total phenolic content}

TPC in mangosteen rind extract was determined using the Folin-Ciocalteu method (Chai \& Wong, 2012). Briefly, $0.2 \mathrm{~mL}$ of the sample $(0.2 \mathrm{mg} / \mathrm{mL}$ in $80 \%(\mathrm{v} / \mathrm{v})$ ethanol) was mixed with $0.8 \mathrm{~mL}$ of distilled water and $0.1 \mathrm{~mL}$ of Folin-Ciocalteu's phenol reagent. The mixture was vortexed and kept in the dark at room temperature for $3 \mathrm{~min}$. Next, $0.3 \mathrm{~mL}$ of $20 \%(\mathrm{w} / \mathrm{v})$ $\mathrm{Na}_{2} \mathrm{CO}_{3}$ solution was added to the mixture followed by further incubation in the dark for $120 \mathrm{~min}$. The absorbance of the mixture was read at $765 \mathrm{~nm}$. A standard curve was prepared using gallic acid solution $(20-100 \mu \mathrm{g} / \mathrm{mL}$ in $80 \%$ (v/v) ethanol). TPC was expressed as milligram of gallic acid equivalent (GAE) per gram of dry extract.

\subsection{2,2-diphenyl-1-picrylhydrazyl (DPPH) free radical scavenging activity}

DPPH free radical scavenging activity of mangosteen rind extract was measured according to a procedure described in Chai \& Wong (2012) with slight modification. Briefly, $1 \mathrm{~mL}$ of sample $(0-2 \mathrm{mg} / \mathrm{mL} 80 \%(\mathrm{v} / \mathrm{v})$ ethanol) was mixed with $1 \mathrm{~mL}$ of DPPH solution $(0.1 \mathrm{mM}$ in $80 \%(\mathrm{v} / \mathrm{v})$ ethanol). The mixture was incubated in the dark at room temperature for $30 \mathrm{~min}$ prior to reading absorbance at $517 \mathrm{~nm}$. Trolox solution $(0-100 \mu \mathrm{g} / \mathrm{mL}$ in $80 \%(\mathrm{v} / \mathrm{v})$ ethanol) was used as standard and the results were expressed as milligram of Trolox equivalent (TE) per gram of dry extract. The percentage of free radical inhibition was also calculated using the Equation 3 below:

$D P P H$ free radical scavenging activity $(\%)=\frac{A_{\text {control }}-A_{\text {extract }}}{A_{\text {control }}} \times 100 \%$

\subsection{Morphological determination of microencapsulated extract}

The morphology of the microencapsulated extract particles was studied using a Schottky Field Emission Scanning Electron Microscope (SEM) (JEOL JSM-7610F, Japan). The sample was mounted onto the surface of a bilateral double-sided adhesive tape that was subsequently attached/ pre-attached to an aluminum stub. Then, the sample was sputter-coated with a thin gold film and viewed under the SEM with an acceleration voltage of $2 \mathrm{kV}$, 10 A emission current, $6 \mathrm{~mm}$ working distance, and 500× and $5000 \times$ magnifications.

\subsection{Statistical analysis}

All analyses were conducted in triplicates and results were reported in mean and standard deviation. Data were subjected to variance analysis (ANOVA), Tukey's HSD test and t-test using SPSS Statistics (IBM Corporation, US). Significant difference was reported at $p<0.05$.

\section{Results and discussion}

\subsection{Crude extract yield, total xanthone content (TXC), total phenolic content (TPC) and antioxidant activity}

Table 2 shows the extraction yield, TXC and TPC of mangosteen rind extracts in 15 responses with different combinations of independent variables. The highest extraction yield (19.43\%)

Table 2. Extraction yield, total xanthone content, total phenolic content and antioxidant activity of mangosteen rind extract.*

\begin{tabular}{|c|c|c|c|c|c|c|c|}
\hline \multirow{2}{*}{ Responses } & \multicolumn{3}{|c|}{ Independent variables } & \multirow{2}{*}{ Yield (\%) } & \multirow{2}{*}{ Total xanthone content } & \multirow{2}{*}{ Total phenolic content $\$$} & \multirow{2}{*}{ Antioxidant activity } \\
\hline & $\mathrm{X}_{1}$ & $\mathrm{X}_{2}$ & $\mathrm{X}_{3}$ & & & & \\
\hline 1 & 0 & $10: 1$ & 6 & $15.81 \pm 0.14^{\mathrm{a}}$ & $40.64 \pm 7.13^{\mathrm{a}}$ & $35.72 \pm 6.41^{\mathrm{a}, \mathrm{b}}$ & $405.19 \pm 61.75^{\mathrm{a}}$ \\
\hline 2 & 2 & $10: 1$ & 6 & $14.39 \pm 0.37^{b}$ & $20.67 \pm 4.06^{c}$ & $16.23 \pm 1.19^{c}$ & $426.94 \pm 17.40^{\mathrm{a}}$ \\
\hline 3 & 0 & $20: 1$ & 6 & $19.43 \pm 0.56^{c}$ & $45.01 \pm 3.79^{\mathrm{a}}$ & $39.54 \pm 2.74^{\mathrm{a}}$ & $403.10 \pm 18.49^{a}$ \\
\hline 4 & 2 & $20: 1$ & 6 & $15.06 \pm 1.30^{\mathrm{a}, \mathrm{b}}$ & $27.95 \pm 5.38^{\mathrm{b}}$ & $24.12 \pm 0.68^{b}$ & $296.85 \pm 40.23^{b}$ \\
\hline 5 & 0 & $15: 1$ & 3 & $18.42 \pm 0.51^{c}$ & $42.18 \pm 1.19^{\mathrm{a}}$ & $40.37 \pm 1.13^{\mathrm{a}}$ & $184.12 \pm 6.74^{\mathrm{d}}$ \\
\hline 6 & 2 & $15: 1$ & 3 & $16.01 \pm 0.80^{\mathrm{a}}$ & $28.70 \pm 1.65^{\mathrm{b}}$ & $21.05 \pm 2.02^{\mathrm{b}, \mathrm{c}}$ & $442.22 \pm 15.97^{\mathrm{a}}$ \\
\hline 7 & 0 & $15: 1$ & 9 & $18.92 \pm 0.54^{\mathrm{c}}$ & $43.84 \pm 4.01^{\mathrm{a}}$ & $45.40 \pm 2.57^{\mathrm{d}}$ & $473.13 \pm 11.98^{\mathrm{a}}$ \\
\hline 8 & 2 & $15: 1$ & 9 & $14.89 \pm 0.61^{\mathrm{b}}$ & $28.76 \pm 5.78^{\mathrm{b}}$ & $24.48 \pm 2.13^{\mathrm{b}}$ & $161.67 \pm 20.57^{c}$ \\
\hline 9 & 1 & $10: 1$ & 3 & $14.53 \pm 0.58^{b}$ & $22.90 \pm 1.87^{\mathrm{b}, \mathrm{c}}$ & $24.74 \pm 1.92^{\mathrm{b}}$ & $376.25 \pm 38.91^{\mathrm{a}}$ \\
\hline 10 & 1 & $20: 1$ & 3 & $17.76 \pm 0.52^{\mathrm{d}}$ & $29.69 \pm 2.85^{b}$ & $25.31 \pm 1.04^{\mathrm{b}}$ & $408.31 \pm 22.44^{\mathrm{a}}$ \\
\hline 11 & 1 & $10: 1$ & 9 & $14.25 \pm 0.66^{\mathrm{b}}$ & $22.53 \pm 4.23^{\mathrm{b}, \mathrm{c}}$ & $19.81 \pm 4.17^{\mathrm{b}, \mathrm{c}}$ & $285.28 \pm 94.47^{\mathrm{a}, \mathrm{b}}$ \\
\hline 12 & 1 & $20: 1$ & 9 & $18.03 \pm 0.93^{c}$ & $32.22 \pm 3.74^{\mathrm{b}}$ & $29.82 \pm 1.04^{\mathrm{b}}$ & $326.71 \pm 77.30^{\mathrm{a}, \mathrm{b}}$ \\
\hline 13 & 1 & $15: 1$ & 6 & $15.43 \pm 0.78^{\mathrm{a}, \mathrm{b}}$ & $29.89 \pm 2.82^{b}$ & $25.61 \pm 2.42^{\mathrm{b}}$ & $188.06 \pm 19.28^{b, c}$ \\
\hline 14 & 1 & $15: 1$ & 6 & $16.07 \pm 0.89^{a}$ & $26.82 \pm 0.37^{\mathrm{b}}$ & $24.11 \pm 1.26^{\mathrm{b}}$ & $336.44 \pm 11.95^{\mathrm{b}}$ \\
\hline 15 & 1 & $15: 1$ & 6 & $17.27 \pm 0.10^{\mathrm{d}}$ & $27.95 \pm 4.53^{\mathrm{b}, \mathrm{c}}$ & $21.97 \pm 2.59^{b}$ & $118.61 \pm 15.77^{c}$ \\
\hline
\end{tabular}

$\mathrm{X}_{1}=$ soaking time $(\mathrm{h}) ; \mathrm{X}_{2}=\mathrm{S} / \mathrm{F}$ ratio; $\mathrm{X}_{3}=$ extraction time $(\mathrm{min}) ;{ }^{*}$ Data are means of three determinations with standard deviations; ${ }^{*} \mathrm{mg} \alpha$-mangostin equivalent/g crude extract; ${ }^{\$} \mathrm{mg}$ gallic acid equivalent/g crude extract; ${ }^{\dagger} \mathrm{DPPH}$ free radical scavenging activity, mg Trolox equivalent/g crude extract; ${ }^{\mathrm{a}-\mathrm{d}}$ Data in each column which are annotated with different superscripts are significantly different $(p<0.05)$. 
was obtained in the third response, and it also contained the highest TXC (45.01 mg $\alpha$-mangostin equivalent/g crude extract), but the TPC (39.54 mg GAE/g crude extract) was slightly lower than the seventh response. The yield and TXC content in the seventh response were not significantly different from the third response but it had the highest TPC (45.40 mg GAE/g crude extract) and antioxidant activity (473.13 mg TE equivalent/g crude extract) among all the responses. It has been reported that soaking increased the yield of plant materials, such as mangiferin from Curcuma amada (Kullu et al., 2013), in solvent due to the hydration mechanisms. Other phenolic compounds from Pistacia lentiscus leaves were also extracted with incorporation of soaking process (Dahmoune et al., 2014). However, the results of this study did not exhibit the same trends as the above studies. Notably, both the third and the seventh responses did not incorporate the soaking process. This discrepancy in relation to the findings of others could be explained by the extraction process, including the use of different types of solvent, time and temperature. Moreover, soaking at room temperature may also encourage oxidation reactions and degradation of some phytochemical compounds (Chaovanalikit et al., 2012), thus reducing their solubilities in the solvent. A study of Suttirak \& Manurakchinakorn (2014) reported that most of the phenolic compounds of mangosteen rind were soluble in medium polar and non-polar solvents. However, taking the food safety into account, as well as considering the reduction of the solvent wastage and the operating cost for future commercial application, the present study only employed distilled water as the extraction solvent. So, the extract was expected to contain a moderate number of polar solutes, such as organic acids, soluble proteins and sugars (Bandar et al., 2013; Rybczynski et al., 2015).

In addition to the aforementioned factors, an increase of solvent-to-feed (S/F) ratio could generally increase the extraction yield of plant materials (Kislik, 2012). This was observed in the third response where the highest amount of xanthone content was obtained in the highest $\mathrm{S} / \mathrm{F}$ ratio 20:1. A similar optimization study of MAE on Actinidia deliciosa root demonstrated that S/F ratio in the range of 10:1 to 20:1 was an optimal condition to obtain triterpenoid (Bai et al., 2007). It has been reported that a higher concentration gradient in relation with more solvent available for the extraction could lead to a higher diffusion rate of compounds (Goldsmith et al., 2014). According to Fang et al. (2011), an increase in extraction time could also result in the increase of the extraction yield. This was also evidenced in this study where the highest TPC was obtained in the seventh response with longer extraction time $(9 \mathrm{~min})$ but lower $\mathrm{S} / \mathrm{F}$ ratio $(15: 1)$ compared to the third response. Nevertheless, different extraction times used in the present study did not show significant effect on the overall crude extract yield for each of the $S / F$ ratios investigated. This phenomenon could be due to insufficient extraction time for releasing phytochemical compounds completely from the plant matrix in the MAE process (Shiddiqi et al., 2015). When the goal is to obtain the highest yield of phytocompounds while preserving their antioxidant activities through the MAE process, the extraction time and temperature are critical. It has been reported that the increase of temperature during extraction would increase the diffusion coefficient and the solubility of plant materials in the solvent (Fang et al., 2011; Mabiki et al., 2013). Yet, the mixture should not be overheated to prevent thermal degradation as well as oxidation of thermolabile compounds which are commonly found in solvents with high dielectric properties, such as water, ethanol and methanol (Veggi et al., 2013; Teles et al., 2018). Therefore, optimization analysis was conducted in this study to obtain the appropriate extraction conditions.

Despite the highest DPPH free radical scavenging activity observed in the seventh response, the antioxidant activities of the 15 responses did not show consistent correlations with either TPC or TXC. For examples, the fifth response possessed the lowest antioxidant activity ( $84.12 \mathrm{mg} \mathrm{GAE} / \mathrm{g}$ crude extract), but had similar TXC with the third and the seventh responses and similar TPC with the third response. The sixth response had significantly different TXC and TPC from the seventh response, but no significant difference was found between their antioxidant activities. The eighth and ninth responses had similar TXC and TPC, although the ninth response showed significantly higher antioxidant activity than the eighth. Although some studies (Fang et al., 2011; Govindan \& Muthukrishnan, 2013) reported positive relationships between TPC and antioxidant activity, the fluctuation of antioxidant data in the present study did not show a similar correlation. It prompted future investigation on the effects of processing parameters on bioavailability or antioxidant potency of TPC. In this study, these data were further analyzed to verify the model fitting in RSM.

\subsection{Modelling and model fitting using response surface methodology}

Figure 1 shows the model fitting of TXC, TPC and antioxidant activity. Results indicated that the mathematical model of TXC, TPC and antioxidant activity have a good fit $(p<0.0001)$ with the actual behavior. The mathematical models of TXC (Figure 1A) and TPC (Figure 1B), with high $\mathrm{R}^{2}$ values and low root mean square error (RMSE) values, indicated high strength of association between independent and dependent variables. The lower F ratio value of TXC (0.7804), in comparison with TPC (1.7668), indicated that the experimental data had lesser variation among groups and were much closer to the predicted data from the TXC model than the TPC data obtained. These valid and reliable models could be applied for maximum recovery of TXC and TPC from mangosteen rinds. On the other hand, as shown in Figure $1 \mathrm{C}$, the predicted antioxidant values under combination of various conditions are not linear to their actual values and mostly fell out of the range, with low $\mathrm{R}^{2}$ value (0.63) and high RMSE value (87.313). Besides, high $F$ ratio value of antioxidant data (5.9326) implied great variation among experimental data groups. In addition, the Prob > F value (0.0025) of the whole model set was less than 0.05 , signifying that the experimental data did not fit into the model. The linear regression of this model indicated an unreliable mathematical model for the prediction of the antioxidant activity in mangosteen rind extract. Thus, the optimization analysis using RSM for the effect of extraction parameters on antioxidant activity was omitted.

\subsection{Response surface analysis}

Figure 2 shows the effects of paired independent variables on TXC (Figures 2A, 2B, 2C) and TPC (Figures 2D, 2E, 2F). In general, the increases of $\mathrm{S} / \mathrm{F}$ ratio and extraction time promoted the yield of both TXC and TPC; on the other hand, the increase of 
soaking time reduced the yield of both TXC and TPC. According to Table 3, the results of analysis of variance indicated that the coefficients $b_{1}, b_{2}$ and $b_{11}$ significantly affected the TXC in the extraction process, suggesting that the soaking time and $\mathrm{S} / \mathrm{F}$ ratio had marked effects on the TXC, but other parameters did not show significant difference. On the other hand, the coefficients of $\mathrm{b}_{1}, \mathrm{~b}_{2}, \mathrm{~b}_{23}, \mathrm{~b}_{11}, \mathrm{~b}_{33}$ significantly affected the TPC in the extraction process, suggesting the soaking process, S/F ratio and extraction time had marked effects on the TPC. As shown in Figure 3, the interaction profiles of independent variables summarized that soaking process had negative correlation, but S/F ratio and extraction time had positive correlation with the yield of both TXC and TPC. Altogether the results showed that 20:1 S/F ratio and 9-min MAE without soaking process were
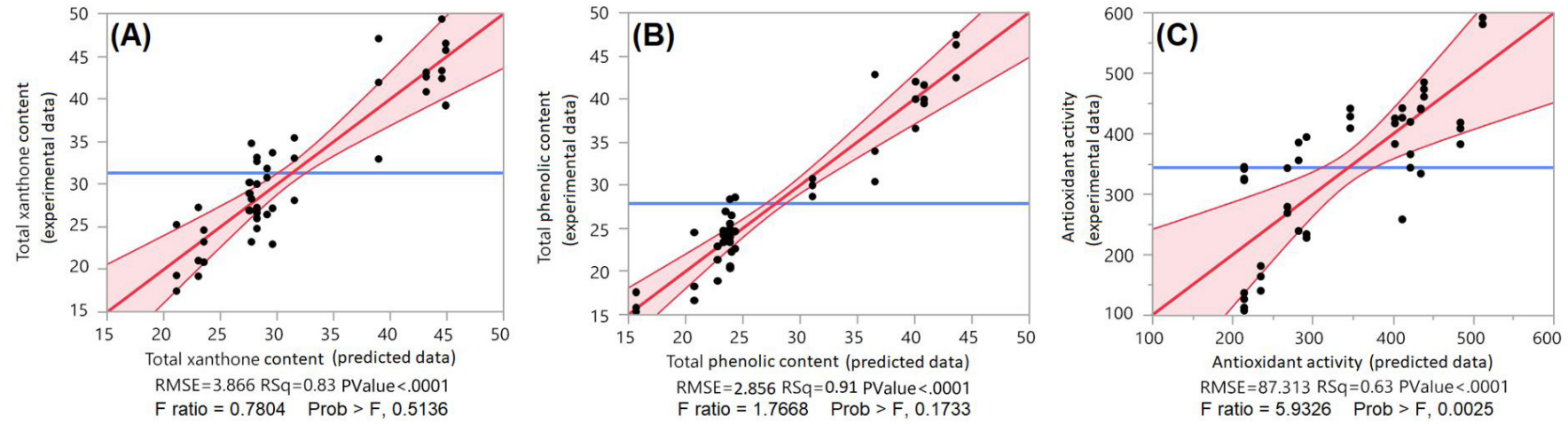

Figure 1. The relationship between actual (experimental data) and predicted values of (A) total xanthone content (mg $\alpha$-mangostin equivalent/g crude extract); (B) total phenolic content (mg gallic acid equivalent/g crude extract); and (C) DPPH free radical scavenging activity (mg Trolox equivalent/g crude extract). Note: Prob $>$ F value less than 0.05 indicates the data do not fit into the model. $\mathrm{Y}_{\text {Total xanthone content }}=28.2244-8.1975 X_{1}+$ $3.5171 X_{2}+0.4863 X_{3}+0.7267 X_{1} X_{2}-0.3983 X_{1} X_{3}+0.7225 X_{2} X_{3}+7.1890-1.8451+0.4582 ; Y_{\text {Total phenolic content }}=23.8978-9.3958 X_{1}+2.7867 X_{2}+$ $1.0050 X_{3}+1.0158 X_{1} X_{2}-0.3958 X_{1} X_{3}+2.3625 X_{2} X_{3}+6.4548-1.4501+2.4715 ; Y_{\text {Antioxidant activity }}=214.3689-75.6508 X_{1}-7.2483 X_{2}-62.1817 X_{3}-$ $31.8275 X_{1} X_{2}-25.7225 X_{1} X_{3}+2.3425 X_{2} X_{3}+108.9776+59.5010+75.2693$; where, $X_{1}$, soaking time $(\mathrm{h}) ; X_{2}, \mathrm{~S} / \mathrm{F}$ ratio; $X_{3}$, extraction time (min).
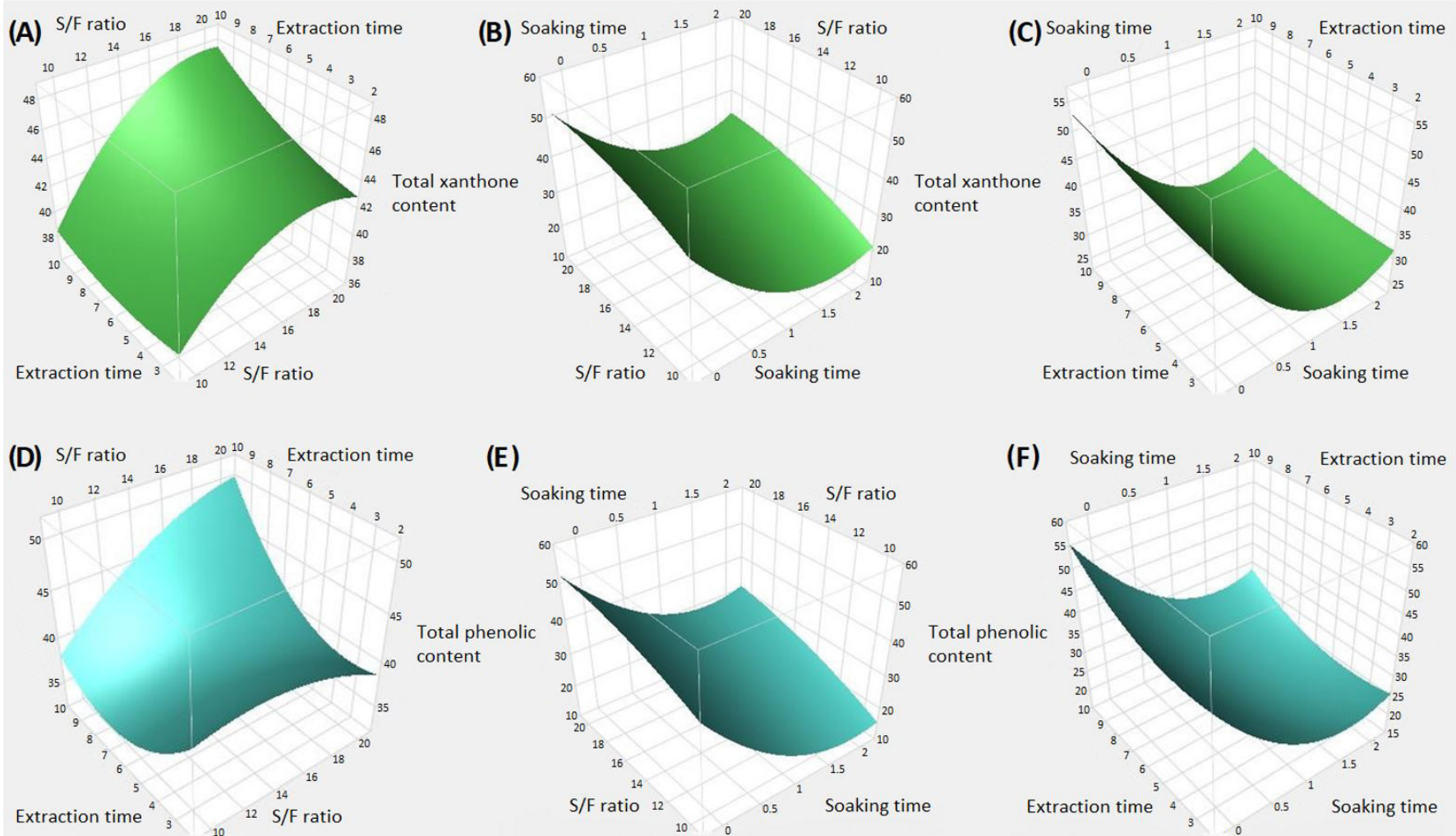

(E)

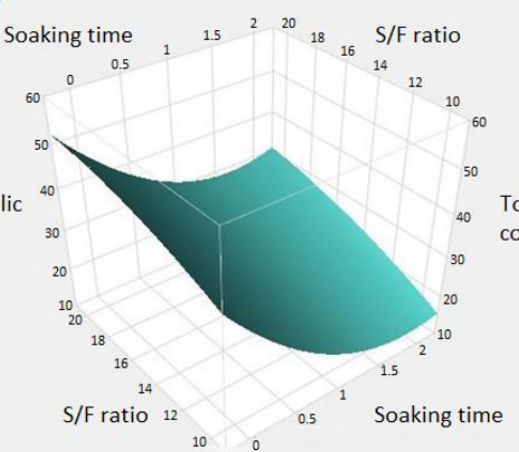

(F)

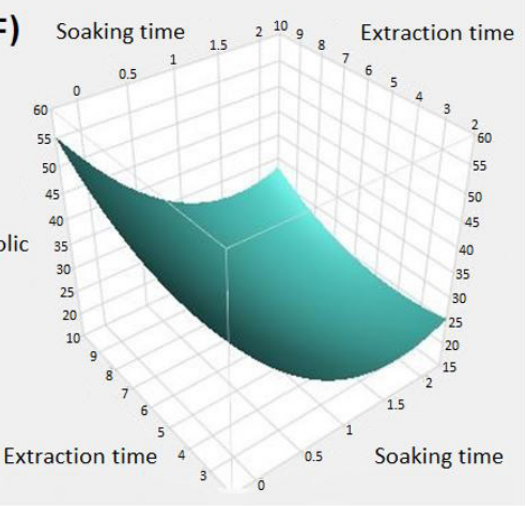

Figure 2. Response surface plots showing the impacts of paired independent variables, including (A, D) S/F ratio and extraction time (min); $(\mathrm{B}, \mathrm{E})$ soaking time $(\mathrm{h})$ and $\mathrm{S} / \mathrm{F}$ ratio; $(\mathrm{C}, \mathrm{F})$ soaking time $(\mathrm{h})$ and extraction time $(\mathrm{min})$; on the predicted $(\mathrm{A}, \mathrm{B}, \mathrm{C})$ total xanthone content (mg a-mangostin/g of crude extract); and (D, E, F) total phenolic content (mg gallic acid equivalent/g crude extract). 
Table 3. Analysis of variance on total xanthone and total phenolic contents.

\begin{tabular}{cccccc}
\hline \multirow{2}{*}{ Coefficients } & \multicolumn{2}{l}{ Total xanthone content ${ }^{*}$} & & \multicolumn{2}{c}{ Total phenolic content } \\
\cline { 2 - 3 } \cline { 5 - 6 } & Estimate & Prob $>|\mathrm{t}|$ & & Estimate & Prob $>|\mathrm{t}|$ \\
\hline $\mathrm{b}_{0}$ & 28.2244 & $<0.0001^{*}$ & & 23.8978 & $<0.0001^{*}$ \\
$\mathrm{~b}_{1}$ & -8.1975 & $<0.0001^{*}$ & & -9.3958 & $<0.0001^{*}$ \\
$\mathrm{~b}_{2}$ & 3.5171 & $<0.0001^{*}$ & & 2.7867 & $<0.0001^{*}$ \\
$\mathrm{~b}_{3}$ & 0.4863 & 0.5418 & & 1.0050 & 0.0935 \\
$\mathrm{~b}_{12}$ & 0.7267 & 0.5192 & & 1.0158 & 0.2261 \\
$\mathrm{~b}_{13}$ & -0.3983 & 0.7233 & & -0.3958 & 0.6341 \\
$\mathrm{~b}_{23}$ & 0.7225 & 0.5216 & & 2.3625 & $0.0070^{*}$ \\
$\mathrm{~b}_{11}$ & 7.1890 & $<0.0001^{*}$ & & 6.4548 & $<0.0001^{*}$ \\
$\mathrm{~b}_{22}$ & -1.8451 & 0.1212 & & -1.4501 & 0.0999 \\
$\mathrm{~b}_{33}$ & 0.4582 & 0.6956 & & 2.4715 & $0.0067^{*}$ \\
\hline
\end{tabular}

$\mathrm{b}_{0}=$ Intercept $\mathrm{b}_{1}, \mathrm{~b}_{2}$, and $\mathrm{b}_{3}=$ Linear regression coefficients for soaking time, $\mathrm{S} / \mathrm{F}$ ratio, and extraction time, respectively; $\mathrm{b}_{11}, \mathrm{~b}_{22}$, and $\mathrm{b}_{33}=$ Quadratic regression coefficients for soaking time $\times$ soaking time, $\mathrm{S} / \mathrm{F}$ ratio $\times \mathrm{S} / \mathrm{F}$ ratio, and extraction time $\times$ extraction time, respectively; $\mathrm{b}_{12}, \mathrm{~b}_{13}$, and $\mathrm{b}_{23}=$ Regression coefficients for interaction between soaking time $\times \mathrm{S} / \mathrm{F}$ ratio, soaking time $\times$ extraction time, and $\mathrm{S} / \mathrm{F}$ ratio $\times$ extraction time, respectively; ${ }^{\#} \mathrm{mg}$ a-mangostin equivalent/g crude extract; ${ }^{\$} \mathrm{mg}$ gallic acid equivalent/g crude extract: *Significantly different $(p<0.05)$

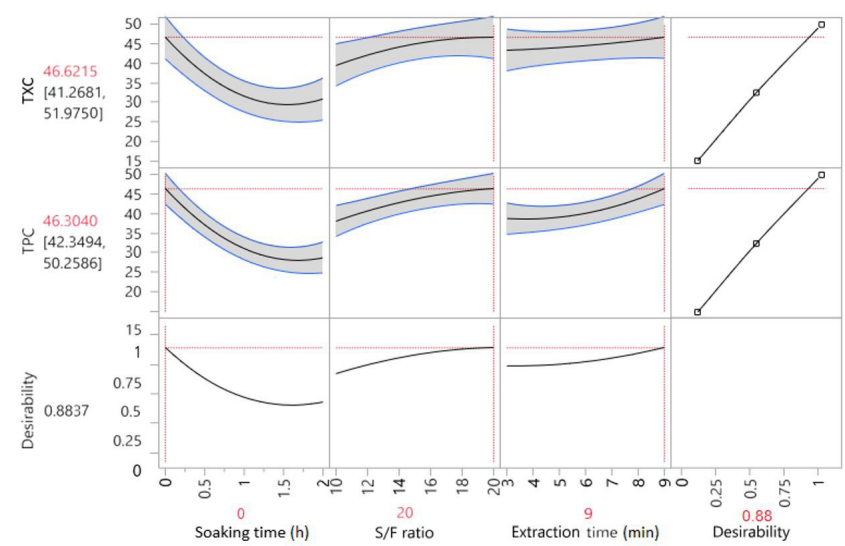

Figure 3. Optimization of soaking time (0-2 h), S/F ratio (10:1-20:1) and extraction time (3-9 $\mathrm{min}$ ) on total xanthone content (TXC) and total phenolic content (TPC).

the optimized parameters within this study for the extraction of TXC and TPC from mangosteen rind.

One of the fundamental extraction parameters that significantly affected the TXC and TPC in this study was the S/F ratio. When increased from 10:1 to 20:1, the extraction yield of TXC and TPC was also increased. This finding is in agreement with a similar study (Bhuyan et al., 2015) which described an increase in extraction efficiency with higher volume of solvent used by means of higher frequency of contact between solid particles and solvent in order to dissolve sample matrix thoroughly into solvent. Furthermore, the interactive effect of $\mathrm{S} / \mathrm{F}$ ratio and extraction time (Figure 2A) significantly increased the yield of TXC and TPC. However, as mentioned previously by Fang et al. (2011), the yield of xanthones was decreased when the extraction time was increased up to 20 min because the xanthone compounds were destroyed with increasing irradiation time. Compared to a narrow range of extraction time used in this study, the operation might not be the optimum extraction time since there was no sign of decrease in TXC and TPC up to $9 \mathrm{~min}$ of extraction. This suggested that the extraction time could be extended to further investigate the impact of extraction time on their yields. Furthermore, Padmapriya et al. (2011) reported that increasing microwave power from $350 \mathrm{~W}$ to $500 \mathrm{~W}$ could significantly enhance the extraction efficiency with only $20 \mathrm{~s}$ of irradiation time. Applying high microwave power can accelerate the extraction of polyphenolic compound because it rises ionic conduction and dipole rotation in purpose to generate molecular movement and heating on the sample matrix (Shao et al., 2012). Therefore, the adverse effects of long extraction time could be prevented by increasing the microwave power. Further studies are required on the extraction efficiency by using different levels of microwave power. In addition, results depicted a correlation between extraction time $(9 \mathrm{~min})$ and $\mathrm{S} / \mathrm{F}$ ratio (20:1). This finding agreed with those of Dailey \& Vuong (2015) and Ghasemzadeh et al. (2017) who reported that the increased $\mathrm{S} / \mathrm{F}$ ratio could accelerate the extraction due to higher heating efficiency under microwave conditions. Besides, the linear effect of S/F ratio $\left(b_{2}\right)$ on both TXC and TPC, and quadric effects of $S / F$ ratio $\times$ extraction time $\left(b_{23}\right)$ and extraction time $\times$ extraction time $\left(b_{33}\right)$ on TPC, significantly improved the overall performance of MAE.

Figures 2B, 2C, 2E, and 2F illustrate the negative interactive effects of soaking time and S/F ratio pair, and soaking time and extraction time pair, respectively, which significantly reduced the yield of TXC and TPC. Although some similar studies (Ameeret al., 2017; Kullu et al., 2013; Pan et al., 2002; Malode et al., 2013) reported that soaking process increased the yield of phytochemical compounds, MAE produced more TXC and TPC without soaking than those sample with soaking process before the extraction. It has been reported that soaking promotes leaching of phytochemical compounds from the food matrix and thus increasing the chances of direct exposure of these components to microwave radiation during extraction (Veggi et al., 2013). In this study, the significant decrease of TXC and TPC with increasing soaking time was observed. Although soaking enhanced the leaching of TXC and TPC, most of these components were denatured during the MAE process, thus contributing to the overall adverse effect. In addition, the types of solvent used for soaking process may also affect the overall extraction efficiency. A similar study suggested that organic solvents, such as ethanol, could enhance the extraction efficiency while polar solvents, such as water, could favorably increase the contact surface area between sample matrix and solvent by facilitating the swelling of cell wall, thus resulting in an increased extraction yield (Ghasemzadeh et al., 2017). The use of only distilled water in the soaking process might not be efficient in pulling out the target components without the participation of organic solvent. In brief, the results of this study showed that the soaking process significantly hindered the MAE performance. Without the soaking process, the increase of extraction time would accelerate the release of target components due to the rise of internal pressure and the rupturing of the plant matrix cell wall (Ghasemzadeh et al., 2017). 


\subsection{Validation of RSM models}

The results obtained from experiments performed using the parameters optimized for TXC and TPC were compared with the predicted results to ratify the accuracy of the model equations. Figure 3 and Table 4 show the maximum yield of TXC (45.71 $\pm 0.67 \mathrm{mg} \alpha$-mangostin equivalent/g crude extract) and TPC (46.16 $\pm 0.18 \mathrm{mg} \mathrm{GAE} / \mathrm{g}$ of crude extract) obtained from the experiment under the optimized conditions with 0.88 of desirability. The predicted results were in close agreement with the experimental results and there was no significant difference $(p>0.05)$ among them when analyzed using paired t-test analysis. Hence, the optimized conditions were valid to obtain maximum TXC and TPC.

\subsection{Microencapsulation of mangosteen rind extract and its effect on TXC, TPC and antioxidant activity}

The microstructure of spray dried mangosteen rind extract exhibited spherical structure with smooth appearance, and some smaller particles with concavities (Figure 4). Aggregation of the smaller particles around the larger particles demonstrated that the microcapsules had amorphous surface instead of crystalline surface (Cano-Chauca et al., 2005). A similar outcome was also observed in a study of microencapsulation of ascorbic acid using sodium alginate as a coating material (Marcela et al., 2016). The concavity structures on the surface of smaller particles were observed clearly when the magnification was increased to $5000 \times$. A study claimed that the formation of deep dents on the microcapsules were the result of shrinkage of the particles due to the rapid water evaporation at high drying temperature during the spray drying process (Rosenberg et al., 1985). A similar observation on spray dried xanthone microcapsules was also reported when inulin was used as the coating material (Lim \& Siow, 2016). Furthermore, the spray dried microcapsules in this study were free of cracks on their surfaces. It indicated an excellent protection effect of sodium alginate on the core of mangosteen rind extract.

The microcapsules were then analyzed for their TXC (29.04 $\pm 1.99 \mathrm{mg}$ a-mangostin equivalent/g crude extract), TPC (5.91 $\pm 0.07 \mathrm{mg}$ GAE$/ g$ crude extract) and antioxidant activity (result not shown). In comparison to the extract obtained under optimized MAE conditions (Table 4), there was an approximately $36.46 \%$ reduction of TXC after the spray drying microencapsulation. A major decline of TPC was also observed with only $12.81 \%$ was retained after the spray drying microencapsulation. The loss of TXC and TPC was mainly caused by the thermal degradation at high drying temperature $\left(180^{\circ} \mathrm{C}\right)$ in the spray drying process. It has been reported that exposure of mangosteen rind extract to temperature $76{ }^{\circ} \mathrm{C}$ and above could lead to significant denaturation of $\alpha$-mangostin (Chen \& Lin, 2007; Suvarnakuta et al., 2011). Another study also showed that about $57 \%$ of anthocyanin was lost during spray drying at temperature of $140{ }^{\circ} \mathrm{C}$ (Wilkowska et al., 2016). Significant reduction of TPC was also reported on blackberry extract after being spray dried at temperature up to $160^{\circ} \mathrm{C}$ (Rigon \& Zapata Noreña, 2016). On the other hand, other studies demonstrated minimal or no thermal degenerative effect on TPC, for example in the olive pomace extract (Paini et al., 2015) and bayberry

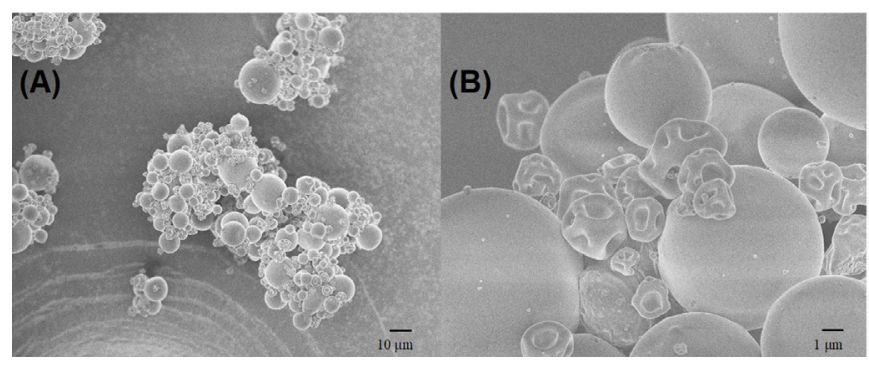

Figure 4. Scanning electron micrographs of microencapsulated mangosteen rind powders under magnifications of (A) 500x; and (B) 5000×.

Table 4. Effect of spray drying microencapsulation on total xanthone content and total phenolic content of optimized mangosteen rind extract. *

\begin{tabular}{lcc}
\hline \multicolumn{1}{c}{ Mangosteen rind extract } & $\begin{array}{c}\text { Total xanthone } \\
\text { content }^{\#}\end{array}$ & $\begin{array}{c}\text { Total phenolic } \\
\text { content }^{\$}\end{array}$ \\
\hline $\begin{array}{l}\text { Predicted by using optimized } \\
\text { model }\end{array}$ & $46.62 \pm 5.35^{\mathrm{a}}$ & $46.30 \pm 3.95^{\mathrm{a}}$ \\
$\begin{array}{l}\text { Optimized extract } \\
\text { Spray dried optimized extract }\end{array}$ & $29.04 \pm 1.99^{\mathrm{b}}$ & $5.91 \pm 0.07^{\mathrm{b}}$ \\
\hline${ }^{*}$ Data are means of three determinations with standard deviations; ${ }^{*} \mathrm{mg}$ a-mangostin \\
equivalent/g crude extract; ${ }^{\$}$ mg gallic acid equivalent/g crude extract; ${ }^{\mathrm{a}-\mathrm{b}}$ Data in each \\
column which are annotated with different superscripts are significantly different \\
$(p<0.05)$.
\end{tabular}

extract (Fang \& Bhandari, 2011), during spray drying process, although high inlet temperature (up to $160^{\circ} \mathrm{C}$ ) was applied. These inconsistent outcomes prompted further investigation on the suitability of using different coating materials, such as maltodextrin and gum arabic, in spray drying microencapsulation under various conditions, such as different inlet temperatures, is necessary to prevent the loss of these thermolabile compounds. The functionality and efficiency of the coating materials should also be clarified. In addition, the present study also observed that the spray drying process caused a significant reduction of DPPH free radical scavenging activity in the extract. This phenomenon can be explained by the intense losses of TXC and TPC during the spray drying process, as positive correlation between these components and the antioxidant activity has been well established (Fang \& Bhandari, 2011; Chaovanalikit et al., 2012).

\section{Conclusions}

In summary, the increase of $\mathrm{S} / \mathrm{F}$ ratio and extraction time in MAE significantly enhanced the extraction yield of mangosteen rind crude extract, TXC and TPC, but the increase of soaking time did not. The third response exhibited the highest yield of crude extract $(19.43 \% \mathrm{w} / \mathrm{w})$. The interactive effects among S/F ratio and extraction time predicted using RSM established the optimal MAE conditions as 20:1 S/F ratio, 9-min extraction time, with 0 -hour soaking time. Under these parameters, the yields of TXC and TPC predicted by the RSM models were further validated with the experimental data under the same parameters. However, the effect of these extraction parameters on the antioxidant activity could not be established in the present study as the collected data did not produce a fitting model $\left(\mathrm{R}^{2}=0.63\right)$. Although the spray drying microencapsulation process caused a 
remarkable degradation of TXC, TPC and antioxidant activity, the performed parameters produced decent shape and appearance of microcapsules which suggested the effectiveness of sodium alginate to enclose the bioactive components completely. The outcomes of this study provide a fundamental knowledge on the optimization of MAE for phytochemical extraction and can aid future exploration on preservation of thermal sensitive bioactive compounds in the mangosteen rind extract.

\section{Conflicts of interest}

The authors declare no conflict of interest.

\section{Author contributions}

Formal analysis, Choi-Wen Hiew, Li-Juan Lee, Kah-Yaw Ee; investigation, Choi-Wen Hiew, Li-Juan Lee; writing original draft preparation, Kah-Yaw Ee; supervision, review and editing, Silvara Junus, Yen-Nee Tan, Tsun-Thai Chai, Kah-Yaw Ee; visualization, Kah-Yaw Ee. All authors have read and agreed to the published version of the manuscript.

\section{Acknowledgements}

This research was supported by Faculty of Science, Universiti Tunku Abdul Rahman, Malaysia, and MaoShanWang Durian Sdn. Bhd., Malaysia. The authors thank MaoShanWang Durian Sdn. Bhd., Malaysia, for supplying fresh mangosteen rind and providing financial assistance.

\section{References}

Aisha, A. F., Abu-Salah, K. M., Ismail, Z., \& Majid, A. M. S. A. (2013). Determination of total xanthones in Garcinia mangostana fruit rind extracts by ultraviolet (UV) spectrophotometry. Journal of Medicinal Plants Research, 7(1), 29-35.

Aliakbarian, B., Sampaio, F. C., Faria, J. T., Pitangui, C. G., Lovaglio, F., Casazza, A. A., Converti, A., \& Perego, P. (2018). Optimization of spray drying microencapsulation of olive pomace polyphenols using response surface methodology and artificial neural network. LWT, 93, 220-228. http://dx.doi.org/10.1016/j.lwt.2018.03.048.

Ameer, K., Shahbaz, H. M., \& Kwon, J. H. (2017). Green extraction methods for polyphenols from plant matrices and their byproducts: a review. Comprehensive Reviews in Food Science and Food Safety, 16(2), 295-315. http://dx.doi.org/10.1111/1541-4337.12253. PMid:33371540.

Bai, X., Qiu, A., \& Guan, J. (2007). Optimization of microwave-assisted extraction of antihepatotoxic triterpenoid from Actinidia deliciosa root and its comparison with conventional extraction methods. Food Technology and Biotechnology, 45(2), 174-180.

Ballesteros, L. F., Ramirez, M. J., Orrego, C. E., Teixeira, J. A., \& Mussatto, S. I. (2017). Encapsulation of antioxidant phenolic compounds extracted from spent coffee grounds by freeze-drying and spray-drying using different coating materials. Food Chemistry, 237, 623-631. http://dx.doi.org/10.1016/j.foodchem.2017.05.142. PMid:28764044.

Bandar, H., Hijazi, A., Rammal, H., Hachem, A., Saad, Z., \& Badran, B. (2013). Techniques for the extraction of bioactive compounds from Lebanese Urtica dioica. American Journal of Phytomedicine and Clinical Therapeutics, 1(6), 507-513.

Bhuyan, D., Van Vuong, Q., Chalmers, A., van Altena, I., Bowyer, M., \& Scarlett, C. (2015). Microwave-assisted extraction of Eucalyptus robusta leaf for the optimal yield of total phenolic compounds.
Industrial Crops and Products, 69, 290-299. http://dx.doi.org/10.1016/j. indcrop.2015.02.044.

Böger, B. R., Georgetti, S. R., \& Kurozawa, L. E. (2018). Microencapsulation of grape seed oil by spray drying. Food Science and Technology, 38(2), 263-270. http://dx.doi.org/10.1590/fst.04417.

Bumrungpert, A., Kalpravidh, R., Chuang, C., Overman, A., Martinez, K., Kennedy, A., \& McIntosh, M. (2010). Xanthones from mangosteen inhibit inflammation in human macrophages and in human adipocytes exposed to macrophage-conditioned media. The Journal of Nutrition, 140(4), 842-847. http://dx.doi.org/10.3945/ jn.109.120022. PMid:20181789.

Cano-Chauca, M., Stringheta, P. C., Ramos, A. M., \& Cal-Vidal, J. (2005). Effect of the carriers on the microstructure of mango powder obtained by spray drying and its functional characterization. Innovative Food Science \& Emerging Technologies, 6(4), 420-428. http://dx.doi.org/10.1016/j.ifset.2005.05.003.

Chai, T.-T., \& Wong, F.-C. (2012). Antioxidant properties of aqueous extracts of Selaginella willdenowii. Journal of Medicinal Plants Research, 6(7), 1289-1296.

Chaovanalikit, A., Mingmuang, A., Kitbunluewit, T., Choldumrongkool, N., Sondee, J., \& Chupratum, S. (2012). Anthocyanin and total phenolics content of mangosteen and effect of processing on the quality of mangosteen products. International Food Research Journal, 19(3), 1047-1053.

Chen, L., Yang, L., \& Wang, C. (2008). Anti-inflammatory activity of mangostins from Garcinia mangostana. Food and Chemical Toxicology, 46(2), 688-693. http://dx.doi.org/10.1016/j.fct.2007.09.096. PMid:18029076.

Chen, Y. T., \& Lin, K. W. (2007). Effects of heating temperature on the total phenolic compound, antioxidative ability and the stability of dioscorin of various yam cultivars. Food Chemistry, 101(3), 955-963. http://dx.doi.org/10.1016/j.foodchem.2006.02.045.

Dahmoune, F., Spigno, G., Moussi, K., Remini, H., Cherbal, A., \& Madani, K. (2014). Pistacia lentiscus leaves as a source of phenolic compounds: microwave-assisted extraction optimized and compared with ultrasound- assisted and conventional solvent extraction. Industrial Crops and Products, 61, 31-40. http://dx.doi.org/10.1016/j. indcrop.2014.06.035.

Dailey, A., \& Vuong, Q. (2015). Optimum conditions for microwave assisted extraction for recovery of phenolic compounds and antioxidant capacity from macadamia (Macadamia tetraphylla) skin waste using water. Processes, 4(1), 2. http://dx.doi.org/10.3390/pr4010002.

Fang, L., Liu, Y., Zhuang, H., Liu, W., Wang, X., \& Huang, L. (2011). Combined microwave-assisted extraction and high-speed countercurrent chromatography for separation and purification of xanthones from Garcinia mangostana. Journal of Chromatography B, 879(28), 3023-3027. http://dx.doi.org/10.1016/j.jchromb.2011.08.040. PMid:21925972.

Fang, Z., \& Bhandari, B. (2011). Effect of spray drying and storage on the stability of bayberry polyphenols. Food Chemistry, 129(3), 1139-1147. http://dx.doi.org/10.1016/j.foodchem.2011.05.093. PMid:25212349.

Ferreira, S. L. C., Bruns, R., Ferreira, H., Matos, G., David, J., Brandão, G., da Silva, E., Portugal, L., dos Reis, P., Souza, A., \& dos Santos, W. (2007). Box-Behnken design: An alternative for the optimization of analytical methods. Analytica Chimica Acta, 597(2), 179-186. http:// dx.doi.org/10.1016/j.aca.2007.07.011. PMid:17683728.

Francis, F., Sabu, A., Nampoothiri, K., Ramachandran, S., Ghosh, S., Szakacs, G., \& Pandey, A. (2003). Use of response surface methodology for optimizing process parameters for the production of $\alpha$-amylase 
by Aspergillus oryzae. Biochemical Engineering Journal, 15(2), 107115. http://dx.doi.org/10.1016/S1369-703X(02)00192-4.

Garofulic, I. E., Zoric, Z., Pedisic, S., \& Dragovic-Uzelac, V. (2017). Retention of polyphenols in encapsulated sour cheery juice in dependence of drying temperature and wall material. LWT, 83, 110-117. http://dx.doi.org/10.1016/j.lwt.2017.05.017.

Ghasemzadeh, A., Jaafar, H., Rahmat, A., \& Swamy, M. (2017). Optimization of microwave-assisted extraction of zerumbone from Zingiber zerumbet L. rhizome and evaluation of antiproliferative activity of optimized extracts. Chemistry Central Journal, 11(1), 5. http://dx.doi.org/10.1186/s13065-016-0235-3. PMid:28123448.

Goldsmith, C. D., Vuong, Q. V., Stathopoulos, C. E., Roach, P. D., \& Scarlett, C. J. (2014). Optimization of the aqueous extraction of phenolic compounds from olive leaves. Antioxidants, 3(4), 700-712. http://dx.doi.org/10.3390/antiox3040700. PMid:26785235.

Govindan, P., \& Muthukrishnan, S. (2013). Evaluation of total phenolic content and free radical scavenging activity of Boerhavia erecta. Journal of Acute Medicine, 3(3), 103-109. http://dx.doi.org/10.1016/j. jacme.2013.06.003.

Johnson, J. J., Petiwala, S., Syed, D., Rasmussen, J., Adhami, V., Siddiqui, I., Kohl, A., \& Mukhtar, H. (2012). a-Mangostin, a xanthone from mangosteen fruit, promotes cell cycle arrest in prostate cancer and decreases xenograft tumor growth. Carcinogenesis, 33(2), 413-419. http://dx.doi.org/10.1093/carcin/bgr291. PMid:22159229.

Jung, H.-A., Su, B.-N., Keller, W. J., Mehta, R. G., \& Kinghorn, A. D. (2006). Antioxidant xanthones from pericarp of Garcinia mangostana (Mangosteen). Journal of Agricultural and Food Chemistry, 54(6), 2077-2082. http://dx.doi.org/10.1021/jf052649z. PMid:16536578.

Kislik, V. S. (2012). Solvent extraction: classical and novel approaches. Oxford: Elsevier.

Kullu, J., Dutta, A., Constales, D., Chaudhuri, S., \& Dutta, D. (2013). Experimental and modeling studies on microwave-assisted extraction of mangiferin from Curcuma amada. 3 Biotech, 4(2), 107-120.

Lim, Y. H., \& Siow, L. F. (2016). Spray dried xanthone in oil emulsion using inulin as wall material. Journal of Food Processing and Preservation, 41(4), 1-10.

Mabiki, F. P., Magadula, J. J., Mdegela, R. H., \& Mosha, R. D. (2013). Optimization of extraction conditions and phytochemical screening of root extract of Synadenium glaucescens Pax. International Journal of Chemistry, 5(4), 103-112. http://dx.doi.org/10.5539/ijc.v5n4p103.

Makhonpas, C., Phongsamran, S., \& Silasai, A. (2015). Survey of mangosteen clones with distinctive morphology in eastern of Thailand. Agricultural Technology, 11(2), 227-242.

Malode, Y., Hadkar, U. B., Dhruv, N., \& Chavan, B. (2013). Microwave assisted extraction of phytoconstituents. Asian Journal of Phytomedicine and Clinical Research, 2(3), 73-86.

Marcela, F., Lucia, C., Esther, F., \& Elena, M. (2016). Microencapsulation of L- ascorbic acid by spray drying using sodium alginate as wall material. Journal of Encapsulation and Adsorption Sciences, 6(1), 1-8. http://dx.doi.org/10.4236/jeas.2016.61001.

Mazimba, O., Nana, F., Kuete, V., \& Singh, G. S. (2013). Xanthones and anthranoids from the medicinal plants of Africa. In V. Kuete (Ed.), Medicinal plant research in Africa. (pp. 393-434). London: Elsevier Inc. http://dx.doi.org/10.1016/B978-0-12-405927-6.00011-4.

Negi, J. S., Bisht, V. K., Singh, P., Rawat, M. S. M., \& Joshi, G. P. (2013). Naturally occurring xanthones: chemistry and biology. Journal of Applied Chemistry, 2013(9)

Padmapriya, K., Dutta, A., Chaudhuri, S., \& Dutta, D. (2011). Microwave assisted extraction of mangiferin from Curcuma amada. 3 Biotech, 2(1), 27-30.
Paini, M., Aliakbarian, B., Casazza, A. A., Lagazzo, A., Botter, R., \& Perego, P. (2015). Microencapsulation of phenolic compounds from olive pomace using spray drying: a study of operative parameters. LWT, 62(1), 177-186. http://dx.doi.org/10.1016/j.lwt.2015.01.022.

Pan, X., Niu, G., \& Liu, H. (2002). Comparison of microwave-assisted extraction and conventional extraction techniques for the extraction of tanshinones from Salvia miltiorrhiza bunge. Biochemical Engineering Journal, 12(1), 71-77. http://dx.doi.org/10.1016/S1369703X(02)00039-6.

Pothitirat, W., \& Gritsanapan, W. (2008). Quantitative analysis of total mangostins in Garcinia mangostana fruit rind. Journal of Health Research, 22(4), 161-166.

Rigon, R. T., \& Zapata Noreña, C. P. Z. (2016). Microencapsulation by spray-drying of bioactive compounds extracted from blackberry (Rubus fruticosus). Journal of Food Science and Technology, 53(3), 15151524. http://dx.doi.org/10.1007/s13197-015-2111-x. PMid:27570276.

Rosenberg, M., Kopelman, I. J., \& Talmon, Y. (1985). A scanning electron microscopy study of microencapsulation. Journal of Food Science, 50(1), 139-144. http://dx.doi.org/10.1111/j.1365-2621.1985.tb13295.x.

Rybczynski, J. J., Davey, M. R., \& Mikula, A. (2015). The gentianaceae: biotechnology and application (Vol. 2). Berlin: Springer-Verlag:

Satong-aun, W., Assawarachan, R., \& Noomhorm, A. (2011). The influence of drying temperature and extraction methods on a-mangostin in mangosteen pericarp. Journal of Food Science and Engineering, 1, 85-92.

Shao, P., He, J., Sun, P., \& Zhao, P. (2012). Analysis of conditions for microwave-assisted extraction of total water-soluble flavonoids from Perilla frutescens leaves. Journal of Food Science and Technology, 49(1), 66-73. http://dx.doi.org/10.1007/s13197-011-0265-8. PMid:23572827.

Shibata, M. A., Matoba, Y., Tosa, H., \& Iinuma, M. (2013). Effects of mangosteen pericarp extracts against mammary cancer. Alternative \& Integrative Medicine, 2(8), 1-6.

Shiddiqi, Q. Y. A., Karisma, A. D., Machmudah, S., Widiyastuti, W., Nurtono, T., Winardi, S., Wahyudiono, W., \& Goto, M. (2015). Effect of hydrothermal extraction condition on the content of phenolic compound extracted from rind of mangosteen (Garcinia mangostana) and its antioxidant efficiency. The Journal for Technology and Science, 25(2), 54-59.

Singh, M. N., Hemant, K. S. Y., Ram, M., \& Shivakumar, H. G. (2010). Microencapsulation: a promising technique for controlled drug delivery. Research in Pharmaceutical Sciences, 5(2), 65-77. PMid:21589795.

Sukatta, U., Takenaka, M., Ono, H., Okadome, H., Sotome, I., Nanayama, K., Thanapase, W., \& Isobe, S. (2013). Distribution of major xanthones in the pericarp, aril, and yellow gum of mangosteen (Garcinia mangostana Linn.) fruit and their contribution to antioxidative activity. Bioscience, Biotechnology, and Biochemistry, 77(5), 984-987. http://dx.doi.org/10.1271/bbb.120931. PMid:23649258.

Sutono, T. (2013). Efficacy of Garcinia mangostana L. (mangosteen rind extract) to reduce acne severity. Medical Journal of Indonesia, 22(3), 167-171. http://dx.doi.org/10.13181/mji.v22i3.586.

Suttirak, W., \& Manurakchinakorn, S. (2014). In vitro antioxidant properties of mangosteen peel extract. Journal of Food Science and Technology, 51(12), 3546-3558. http://dx.doi.org/10.1007/s13197012-0887-5. PMid:25477623.

Suvarnakuta, P., Chaweerungrat, C., \& Devahastin, S. (2011). Effects of drying methods on assay and antioxidant activity of xanthones in mangosteen rind. Food Chemistry, 125(1), 240-247. http://dx.doi. org/10.1016/j.foodchem.2010.09.015.

Tatke, P., \& Jaiswal, Y. (2011). An overview of microwave assisted extraction and its applications in herbal drug research. Research Journal of Medicinal Plant, 5(1), 21-31. http://dx.doi.org/10.3923/ rjmp.2011.21.31. 
Teles, A. S. C., Chávez, D. W. H., Gomes, F. D. S., Cabral, L. M. C., \& Tonon, R. V. (2018). Effect of temperature on the degradation of bioactive compounds of Pinot Noir grape pomace during drying. Brazilian Journal of Food Technology, 21, e2017059.

Tjahjani, S., Widowati, W., Khiong, K., Suhendra, A., \& Tjokropranoto, R. (2014). Antioxidant properties of Garcinia mangostana L. (Mangosteen) rind. Procedia Chemistry, 13, 198-203. http://dx.doi. org/10.1016/j.proche.2014.12.027.

Veggi, P. C., Martinez, J., \& Meireles, M. A. A. (2013). Fundamentals of microwave extraction. In F. Chemat, \& G. Cravotto (Eds.), Microwave-assisted extraction for bioactive compounds: theory and practice, food engineering series 4. (pp. 15-52). New York: Springer Science+Business Media.

Waterhouse, G. I. N., Sun-Waterhouse, D., Su, G. W., Zhao, H. F., \& Zhao, M. M. (2017). Spray-drying of antioxidant-rich blueberry waste extracts. Food and Bioprocess Technology, 10(6), 1074-1092. http://dx.doi.org/10.1007/s11947-017-1880-9.
Widowati, W., Darsono, L., Suherman, J., Yelliantty, Y., \& Maesaroh, M. (2014). High performance liquid chromatography (HPLC) analysis, antioxidant, antiaggregation of mangosteen peel extract (Garcinia mangostana L.). International Journal of Bioscience, Biochemistry, Bioinformatics, 4(6), 458-466. http://dx.doi.org/10.17706/ ijbbb.2014.4.6.458-466.

Wilkowska, A., Ambroziak, W., Czyzowska, A., \& Adamiec, J. (2016). Effect of microencapsulation by spray-drying and freeze-drying technique on the antioxidant properties of blueberry (Vaccinium myrtillus) juice polyphenolic compounds. Polish Journal of Food and Nutrition Sciences, 66(1), 11-16. http://dx.doi.org/10.1515/ pjfns-2015-0015.

Wittenauer, J., Falk, S., Schweiggert-Weisz, U., \& Carle, R. (2012). Characterisation and quantification of xanthones from the aril and pericarp of mangosteens (Garcinia mangostana L.) and a mangosteen containing functional beverage by HPLC-DAD-MS. Food Chemistry, 134(1), 445-452. http://dx.doi.org/10.1016/j.foodchem.2012.02.094. 